This item was submitted to Loughborough's Research Repository by the author.

Items in Figshare are protected by copyright, with all rights reserved, unless otherwise indicated.

\title{
Engineering movement into automotive seating: Does the driver feel more comfortable and refreshed?
}

PLEASE CITE THE PUBLISHED VERSION

https://doi.org/10.1016/j.apergo.2018.08.024

PUBLISHER

(C) Elsevier

VERSION

AM (Accepted Manuscript)

\section{PUBLISHER STATEMENT}

This paper was accepted for publication in the journal Applied Ergonomics and the definitive published version is available at https://doi.org/10.1016/j.apergo.2018.08.024.

\section{LICENCE}

CC BY-NC-ND 4.0

\section{REPOSITORY RECORD}

Varela, Maria, Diane E. Gyi, Neil J. Mansfield, Richard Picton, Akinari Hirao, and Tomokazu Furuya. 2019. "Engineering Movement into Automotive Seating: Does the Driver Feel More Comfortable and Refreshed?". figshare. https://hdl.handle.net/2134/34896. 


\title{
Engineering movement into automotive seating: does the driver feel more comfortable and refreshed?
}

\author{
Maria Varela1, Diane Gyi ${ }^{1 *}$, Neil Mansfield ${ }^{2}$, Richard Picton ${ }^{3}$, Akinari Hirao ${ }^{4}$, \\ Tomokazu Furuya ${ }^{4}$ \\ ${ }^{1}$ Loughborough Design School, Loughborough University, United Kingdom \\ ${ }^{2}$ School of Science and Technology, Nottingham Trent University, United Kingdom \\ ${ }^{3}$ Nissan Technical Centre Europe, United Kingdom \\ ${ }^{4}$ Nissan Motor Company Limited, Japan \\ * Corresponding author. Tel.: + 44-1509-223043. E-mail address: D.E.Gyi@lboro.ac.uk
}

\begin{abstract}
The concept of introducing movement in automotive seating was investigated. Three seat conditions, a control (no movement) and two movement conditions (fore-aft and cushionbackrest) were compared. Movement was introduced at a fixed speed, slow, smooth and within a small range. Ten participants took part in a 60 minute simulated drive for each condition - single blind, repeated measures, and balanced order. Discomfort ratings were collected for six body areas and overall discomfort, together with a wellbeing questionnaire. Driver posture and Seat Fidgets and Movements (SFMs) were captured. There was a trend for lower ratings of discomfort, overall and in the neck, shoulders, lower back, buttocks, and ankles with both seat movement conditions. Wellbeing ratings were also better with movement. Significant differences were found at minute 60 for buttock discomfort - less discomfort with seat movement. Overall discomfort and SFMs frequency increased with time driving. Generally, passive seat movement was well received.
\end{abstract}

Keywords: driving; comfort; car seat design; musculoskeletal; ergonomics methods

\section{Introduction}

Good vehicle seat design can positively impact driver musculoskeletal fatigue and lead to improved driver comfort, performance, wellbeing and safety. Fatigue results from the complex interaction of environmental, psychological, biological and vehicle factors exacerbated by conditions such as vibration, long duration sitting or high-workload driving (Jagannath and Balasubramanian, 2014). Grieco (1986) used the term 'postural fixity' to describe the static head, neck and trunk postures of individuals that sit in the same position for long periods of time without significant postural movement. The concept can be applied to drivers, whose posture is fixed by the pedals, steering wheel, seat belt, visual demands of the task and the seat itself (Kolich and Taboun, 2002b). Fixed postures from prolonged driving involve static muscle work and consequently blood vessel constriction, particularly in the spine, buttocks and thighs. This static loading of the driver requires musculature to be enlarged, which causes vasoconstriction and consequently blood flow restrictions (Kolich et al., 2001; Sheridan et al., 1991). As a result, local circulatory disruptions occur such that oxygen delivery, nutrient reserves and the removal of metabolic by-products are compromised. It is now be- 
lieved that even low level sustained contractions (less than $5 \%$ of maximum), such as the ones drivers experience, can be problematic (Kolich and Taboun, 2002a). In addition, intervertebral discs have no direct blood supply and consequently depend on low level but frequent pressure changes, to stimulate the pumping of intercellular fluid into and out of the disc to provide nutrients and remove waste products (Kolich et al., 2001).

Static postures can cause local musculoskeletal discomfort (pain, aches, cramps, numbness), psychological fatigue and in the long-term chronical musculoskeletal problems. Indeed, driving for extended periods of time inevitably leads to musculoskeletal symptoms (Porter and Gyi, 2002) and has also been associated with disorders of the spine (Kolich et al., 2001). Other diseases such as deep vein thrombosis can occur in advanced cases (Parakkat et al., 2006). In a well-designed seat the trunk is supported by the backrest, the muscles relax and the lumbar spine is supported. On the contrary, in a poorly designed seat, slouching occurs due to the lack of muscular effort in the trunk, resulting in a loss of lordosis and increase in kyphosis (Gyi, 2013).

Movement provides a useful function of pumping blood into and out of the musculoskeletal system. In the design of the office furniture, the health and comfort benefits of dynamic seating are well established (Groenesteijn et al., 2012). Indeed, Vergara and Page (2002) identified that there should be shifts in posture (macro-movements) approximately every 5 minutes. There are benefits in driving studies too, for example, in a recent study of drivers by Sammonds et al. (2017b), a short break from driving (a 10 minute walk) had beneficial effects on symptoms of discomfort. It is not always possible to take a break from a vehicle, but it has been found that even passive posture changes have positive effects on driver wellbeing (van Veen et al., 2015). Franz et al. (2011) conducted an experimental study where they investigated the effect of a low-intensity massage system in the backrest of car seat. They found that as well as improving driver comfort without distracting the driver, EMG measurements of muscle activity in the shoulders and upper back were reduced. Automotive dynamic sitting can be induced through support mechanisms denominated in literature as micro-adjustment or massage (Kolich et al., 2001) and active seating (e.g., Active Lumbar Systems (Holmes et al., 2013) applied on the lumbar or thoracic region of the spine (Gruevski et al., 2016). Seat configuration variation can also be used to promote passive posture changes, for example, van Veen et al. (2015) conducted a study using a driver seat with varying configuration, $1.5^{\circ}$ movement backwards of the backrest and $1^{\circ}$ upwards and downwards tilt of the seat cushion. The movement condition was better received by participants in terms of less reported discomfort than the static condition. The static no-movement seat also presented more driver fidget movements as well as more discomfort. Maradei et al. (2017) investigated the effect of seat tilt motion from $+5^{\circ}$ to $-5^{\circ}$ and vice versa on low back discomfort on participants with and without low back pain. In this study, a significant decrease in discomfort, due to lumbar pain in the dynamic condition was found.

To sum up, fixed postures and long-term sitting are known to have negative effects on the body as they compromise nutrient exchange. The key to improving driver comfort is to combine good design together with driver behaviour, i.e., design to facilitate a small change of posture to prevent concentration of load and restore blood flow to pressure areas (Gyi, 2013). However, there are few studies focussing on this in terms of current car seat design. 
In this research it was hypothesized that postural movement is beneficial for reducing local musculoskeletal fatigue and discomfort. Engineering movement into the driver seat itself will lead to passive posture variation of the driver: active movement (whereby the driver is encouraged to move) is not suited to the driving task. This concept was investigated through a repeated measures, single blind experimental study involving one hour of simulated driving under three seat conditions - a control (no movement) and two seat movement conditions (fore-aft and cushion-backrest). The movement engineered into the seat changed body contact points with the seat in order to positively affect driver comfort. Therefore, the study aimed to explore musculoskeletal discomfort, feelings of refreshment, wellbeing and comfort in order to ultimately improve the driving experience.

\section{Methods}

\subsection{Sample}

Permission to conduct the study was granted by Loughborough University Ethical Advisory Committee in August 2016. Participants were recruited in the Leicestershire area through local advertising (e.g., posters, email). Ten healthy participants (5 males and 5 females) were recruited with the aim of obtaining a good anthropometric spread. There was no age requirement, but they needed to hold a full UK driving license with at least one full year of driving experience and be regular drivers in the last 12 months.

Participants were asked to wear comfortable, close fitting clothing (no heeled shoes) and not to exercise one hour before the session. In the first session, on participants' arrival, their height and weight were measured.

\subsection{Experimental rig development}

A driving rig was manufactured to provide a repeatable simulation of the driving environment replicating the driving workspace dimensions of a production car. Automatic pedal transmission and a non-adjustable steering wheel were used to control the driving simulator, which was mounted on to a motion platform fixed to a 6 Degrees of Freedom Multi Axis Vibration Simulator (Rexroth Hydraudyne B.V Micro Motion 600-6DoF-200-MK5 MAVIS) with closed loop control. A blackout driving environment was provided and the driving simulation task involved a 3-screen set-up, with four different 'follow driver' scenarios, including town and motorway routes, set up in a fixed sequence. With these scenarios, the participant is required to follow a car; our pilot work indicated that this was preferred to verbal instructions.

Before the first session, a short fitting trial was conducted involving a standard iterative process (Porter and Gyi, 1998), in order to capture participant's self-selected optimum driving position. The seat start position was standardized for these fitting trials (mid fore-aft, mid backrest recline, mid cushion tilt, maximum seat height). Participants 'optimal' seat set-up was then used in all of the experimental conditions. Following this, a system characterisation was carried out with each participant using a Larson Davis Human Vibration Meter 100 (HVM100) to ensure they were exposed to the same target level of seat surface vibration, replicating a UK normal drive. 


\subsection{Seat movement development}

A high-end leather seat from the Nissan Infiniti Q30 (Fig. 1a), with four directions of electronic adjustment - fore-aft, seat height, cushion angle and backrest angle (Fig. 1b) and a memory function was configured for use in the study. It was mounted on to the rig as close as possible to the dimensions of the manufacturer seat set-up of the production car. Due to constraints in availability of parts, for example, steering wheel, pedals, and control panel, it was not possible to replicate the full driving cab set-up.

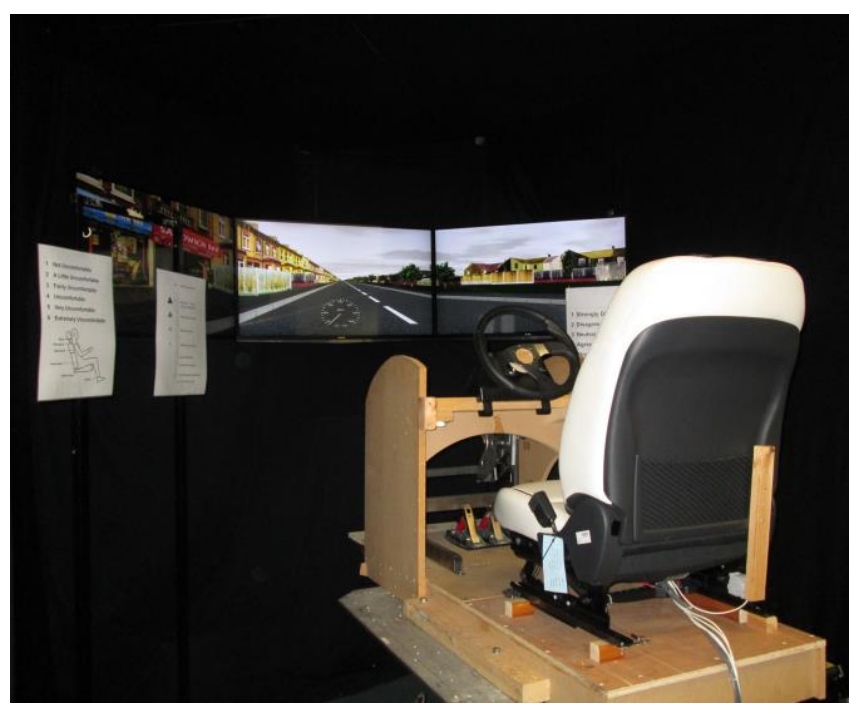

(a)

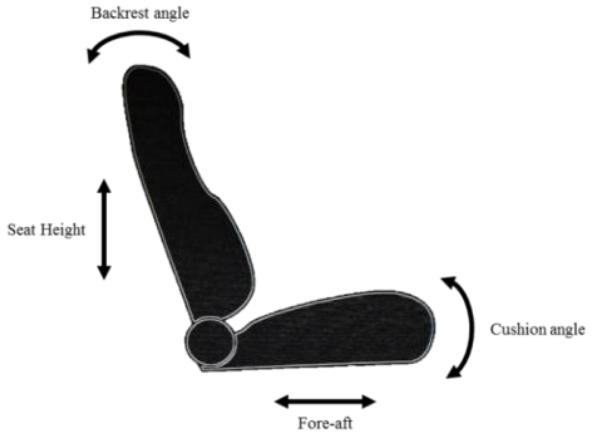

(b)

Fig. 1(a) Simulated driving environment; (b) adjustable directions of seat movement.

Iterative pilot studies were conducted to understand drivers' sensitivity to the seat movement and to help determine the seat movement ranges to be introduced. Seat movement (speed, direction, and range) was limited to the built-in functionality and electronic adjustability offered by the Nissan Infiniti Q3. Independent movement in each direction (fore-aft, seat height, cushion angle and backrest angle) was possible. Unfortunately, several malfunctions of the seat related to the seat lifter motor failing during pilot work lead to the decision not to risk using the seat height (vertical direction of movement) in the study.

A systematic test protocol based on Mansfield and Griffin (2000) was used whereby the seat was gradually moved in small increments until participants reported they were uncomfortable. The first small study $(n=3)$ found that individuals varied in their tolerance to the seat movement iterating that movement needed to be small, smooth and slow. The second pilot study $(n=4)$ concluded that a scale was needed for participant's feedback on the movement. The final pilot study $(n=5)$ aimed to define the seat movement to be tested in the main study. Research questions were:

- Is seat movement perceived?

- What ranges of movement are tolerated for each direction?

- Are there any directions of movement not tolerated? 
- What sequence of movement should be used for the seat?

In general, seat movement was well received although the initial movement was perceived by all participants causing some uncertainty in the first few seconds, but this was quickly overcome. Generally, all directions of movement were tolerated, but as expected, positions too distant from their initial optimum driving position were uncomfortable for individual drivers. The tolerance of range of movement varied between participants, therefore to avoid adversely affecting the driving task, the minimum movement ranges were selected for the main trials.

No conclusions were drawn concerning the preferred type of movement for the seat but it was important that there was no impairment to leg movement, steering, operating the pedals or dashboard view. Also, within the constraints of the production seat, the movement needed to be continuous and at a slow, smooth, fixed speed (the same as the Infiniti Q3), and within a relatively small range of movement, in order to have minimal effect on executing the driving task itself. The seat was therefore moved in gradual, small increments from the start position and involved two movement types (fore-aft and cushion-backrest); the three seat conditions are shown in Table 1.

Table 1. Seat movement conditions under study.

\begin{tabular}{|c|c|c|c|}
\hline Condition & Seat movement & No. of increments & $\begin{array}{l}\text { Total seat movement } \\
\text { (over } 30 \text { minutes) }\end{array}$ \\
\hline 1 & $\begin{array}{l}\text { No movement } \\
\text { (control) }\end{array}$ & 0 & No movement \\
\hline 2 & Fore-aft & $\begin{array}{l}2 \text { increments of } 8 \mathrm{~mm} \\
\text { in each direction } \\
\text { (from start position) }\end{array}$ & $+16 \mathrm{~mm}$ to $-16 \mathrm{~mm}$ \\
\hline \multirow[t]{2}{*}{3} & Cushion-backrest & $\begin{array}{l}\text { Cushion } \\
5 \text { increments of } 1.7^{\circ} \\
\text { in each direction } \\
\text { (from start position) }\end{array}$ & $+8.5^{\circ}$ to $-8.5^{\circ}$ \\
\hline & & $\begin{array}{l}\text { Backrest } \\
2 \text { increments of } 0.5^{\circ} \\
\text { in each direction } \\
\text { (from start position) }\end{array}$ & $+1^{\circ}$ to $-1^{\circ}$ \\
\hline
\end{tabular}

A control system using Daisy Lab Software was developed for remote electronic operation and control of the seat movement by the researcher and the required seat movement was achieved by inputting a specific target position. Finally, pilot work also found that the sound produced by the seat movement motors was perceptible to participants, so insulation was added to minimise this. The driving simulation audio itself also helped to mask the sound. Additionally, to minimise focus on the sound of the movement, three similar sequences of music were played during each of the three conditions. 


\subsection{Data collection}

The three experimental conditions were evaluated on three separate days (1-2 days between sessions), repeated measures design, single blind and in a balanced order. Each session (of approximately 90 minutes) involved a 60 minute simulated driving task. The same protocol was used in accordance with the test condition - only the selected optimum driving position varied between participants. Data collection methods were initially piloted to evaluate their suitability for measuring participant experiences and are summarized below.

Body maps have been used in many studies to evaluate driver discomfort (Gyi and Porter, 1999, Porter et al., 2003, Hiemstra-van Mastrigt et al., 2015, Sammonds et al., 2017a). A body map showing six body areas (neck, shoulders, upper back, lower back, buttock area and ankles) with a six-point Discomfort Scale defined in ISO 2631-1 (International Organization For Standardization, 1997) was used. This was followed by an overall discomfort scale involving an adapted Borg CR-100 scale (Borg and Borg, 2002). Mansfield et al. (2015) used this technique of rating body parts and overall discomfort together effectively. Discomfort scores were collected at baseline and at each 15 minute time point (minute 0, 15, 30, 45, 60) for the 6 body areas together with overall discomfort (Fig. 2). The number of body areas selected focussed on those mainly associated with driving and capturing the potential effects of seat movement. An open-ended question was also asked if participants had discomfort in any 'other' body area. The objective was to achieve minimal disruption to driving but at the same time ensure that the progression of discomfort over time was captured.
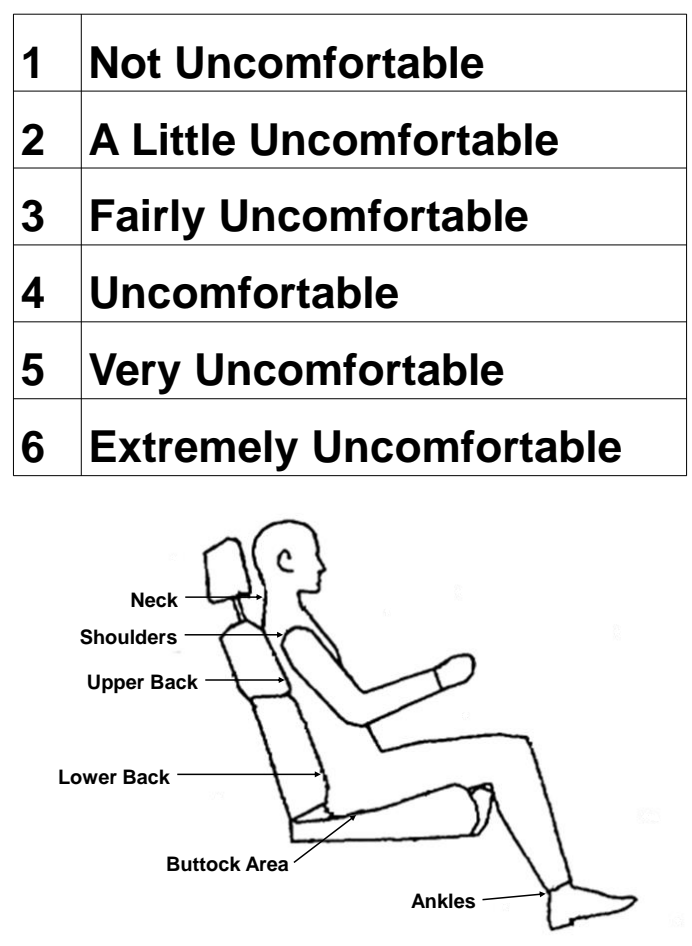

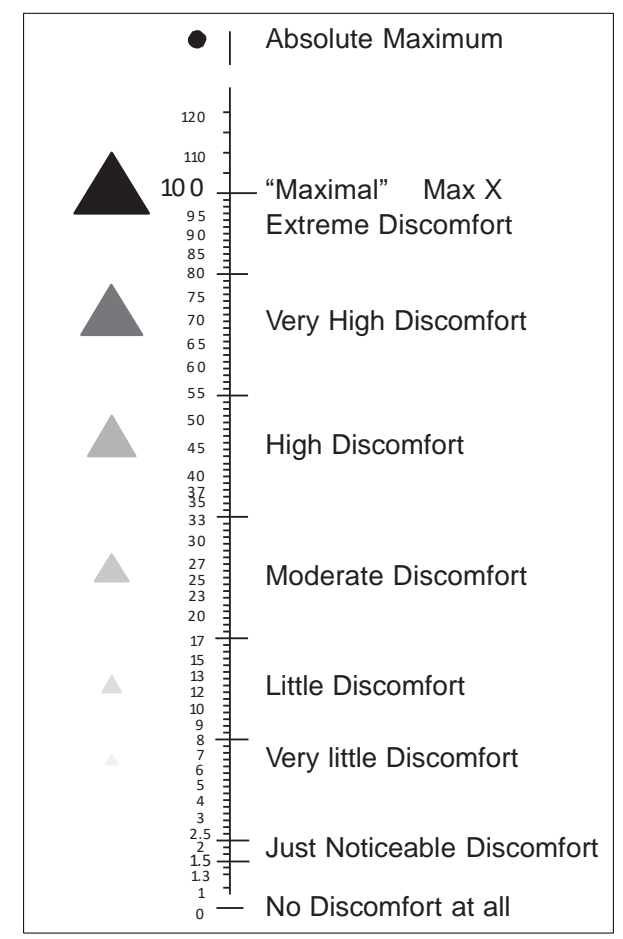

Fig. 2. Discomfort scale adapted from ISO 2631 and Borg CR scale (based on Sammonds et al., 2017a). 
Participants were also asked to complete a wellbeing questionnaire at the beginning and end of each driving session (minute 0 and 60). The descriptors were adapted from Ahmadpour et al. (2015) who investigated aircraft passenger comfort experience. These descriptors are similar to those used in the Chair Evaluation Checklist developed by Helander and Zhang (1997) (based on the work by Zhang et al., 1996). A five-point Likert scale (strongly disagree to strongly agree) was used to rate their responses to:

- I am feeling stiff

- I am feeling relaxed

- I feel refreshed

- I have heavy legs

- I feel numbness in some body parts

- I feel physically fatigued

Prior to the start of the lab trial, participants were trained on the use of the scales ensuring optimum visibility while driving. In the second and third sessions, participants were reminded of the scales. Ratings were given verbally to the researcher whilst driving, i.e. participants did not 'pull over' to provide ratings in order to allow continuous driving for the 60 minute trial. Ratings were also collected at set time points taking account of driver workload, for example, if the driver was about to drive around a corner, the researcher would wait until an appropriate time.

Posture was estimated from the continuous video recordings post trial and used a coding method focussing on the upper body adapted from RULA (Rapid Upper Limb Assessment) (McAtamney and Corlett, 1993). This involved a rank scoring system of the typical driving posture of the driver. The score reflects the postural angles (upper arms, lower arms, wrist, neck, torso, legs) that the participant adopted at the sampled time. The most typical posture within a 5 minute time frame was scored (minute 15, 30, 45 and 60). A Total Score of 7 or more (upper limbs; neck; trunk; and legs) is indicative of a poor posture, for example, $45-90^{\circ}$ arm flexion, $15^{\circ}+$ wrist extension, $10-20^{\circ}$ neck flexion, $0-20^{\circ}$ trunk flexion.

Driver Seat Fidget Movements (SFMs) also known as Discomfort Avoidance Behaviours (DABs) or 'in chair movement' can be used as a measure of driver discomfort (Malik et al., 1991; Maradei et al., 2017, Sammonds et al., 2017a). For the current study SFMs are movements judged to be related to physical discomfort and not to the driving task. Although pressure measurement systems have been used to automatically quantify such movements for example, Maradei et al., (2017) monitored macro-repositioning movements using a pressure mat system, significant review and judgement by the researcher is still needed. There was also concern about the validity of such data for capturing SFMs and that the mat may influence reports of seat discomfort. It was therefore decided to follow a procedure based on Sammonds et al., (2017a) and remotely measure SFMs by detailed reviewing of video recordings post-trial. Due to limitations in the camera set-up, it was not possible to consider lower limb SFMs. All video analysis was standardized (e.g., same video image size) and analysed by the researcher, then checked and uncertainties were reviewed by a second researcher. Analysis was based on the method defined by Sammonds et al. (2017a), whereby the frequency of 
SFMs was counted in time periods of 15 minutes, i.e., 0-15, 15-30, 30-45 and 45-60 (Table 2).

Table 2. SFMs type and description.

\begin{tabular}{ll}
\hline SFM type & Description \\
\hline Type 1 & $\begin{array}{l}\text { Movement of the upper limbs - shoulders and hands included (e.g., arms } \\
\text { stretches) }\end{array}$ \\
Type 2 & $\begin{array}{l}\text { Movement of the upper body that must involve torso or neck (e.g., leaning on } \\
\text { the steering wheel, neck stretch) }\end{array}$ \\
Type 3 & $\begin{array}{l}\text { Whole-body movement that must comprise buttock movement (e.g., shifting } \\
\text { whole body posture) }\end{array}$ \\
\hline
\end{tabular}

It was found to be important to consider the context of when observations were made, therefore as this is a relatively new method for exploring driver discomfort, further detail and rules were added to aid categorisation as follows:

- Uncertainty in classification (following a check with a second researcher) was not counted.

- Continuous SFMs movements, i.e., not clearly separated movements are counted as 1 SFM.

- Movements induced by external influences are not included, for example, movements when completing questionnaires to understand body feelings.

- Examples of movements not classified include sneezes or nose blowing; drinking liquids; moving with the music; scratching; looking in other directions, for example, floor, pedals, watch, leaning to see scales; playing with hair; yawning (which may include neck stretching); removing outer clothing; small change of arm position.

Finally, at the end of the third and final session, a de-brief was given to ensure that perceptions of the seat movement were fully understood and additional comments could be gathered. All statistical analysis was carried out using Statistical Package for the Social Sciences (SPSS).

\section{Results and discussion}

A sample of 10 drivers (5 males and 5 females), aged 19-26, with a stature range of 1554 $\mathrm{mm}$ to $1835 \mathrm{~mm}$, completed the seat movement study.

The ratings of body part and overall discomfort were generally low for all three conditions - this was to some extent expected, due to the use of a high-end production seat: Hiemstravan Mastrigt et al. (2015) also found this when using high quality seats. Indeed, the Friedman test showed that there were no statically significant differences between Condition 1, 2 and 3 at each time period $(0,15,30,45,60$ minutes $)$ for all body parts and overall discomfort as well as for the wellbeing ratings. An exception was buttock area discomfort at 60 minutes (Fig. 3), where a statistically significant difference was found $(\chi 2=7.69, \mathrm{p}=0.021)$, with less reported discomfort for the two 'movement conditions' compared with the 'no movement' condition, and Condition 3 (cushion and backrest angle movement) had the least discomfort. Concerning overall discomfort at 60 minutes, there was again a trend (not statistically signifi- 
cant) for lower ratings with Condition 3, than both Condition 1 (no movement) and Condition 2 .

Using the mean discomfort ratings (over the whole 60 minute drive), once again there was a trend for the two movement conditions ( 2 and 3 ) to have lower ratings than Condition 1 (no movement) for the neck, shoulders, lower back, buttock area and ankles. Condition 2 (foreaft) had lower mean discomfort ratings than Condition 3 (cushion-backrest) for the neck, shoulders, upper back and lower back. However, Condition 3 had lower mean ratings than Condition 2 for the buttock area and ankles. As for mean overall discomfort, Condition 2 had the lowest ratings of discomfort. van Veen et al. (2015) did a study of drivers and found that comfort was significantly better with the seat in a dynamic configuration (passive seat movement) rather than a static over a 45 minute drive. In addition, significantly less discomfort was reported in the neck, lower back and buttocks. Their analysis also concluded that seat movement was particularly beneficial for the lower back.

In line with many other studies (e.g., Sammonds et al., 2017a; Smith et al., 2015; van Veen et al., 2015) there was increased discomfort in driving over time. For all three conditions there were statistically significant differences (Friedman test) in body part discomfort in the neck and lower back and for overall discomfort over time (i.e., at minutes 0, 15, 30, 45 and $60)$ on the 60 minute drive:

- Neck - Condition $1(\chi 2=17.98, \mathrm{p}=0.001)$; Condition $2(\chi 2=13.16, \mathrm{p}=0.011)$; Condition 3 $(\chi 2=14.06, \mathrm{p}=0.007)$

- Lower back - Condition $1(\chi 2=26.10, \mathrm{p}=0)$; Condition $2(\chi 2=19.02, \mathrm{p}=0.001)$; Condition $3(\chi 2=19.17, \mathrm{p}=0.001)$

- Overall discomfort - Condition $1(\chi 2=37.04, p=0)$; Condition $2(\chi 2=31.67, p=0)$; Condition $3(\chi 2=22.04, p=0)$

Of great interest is that when comparing the beginning and end of the trial, drivers reported significantly more discomfort at the end of the trial in all individual body areas (neck, shoulders, upper back, lower back, buttock area, ankles) and for overall discomfort with the no movement condition $(\mathrm{p}<0.001)$. This was not the case for the two movement conditions. 


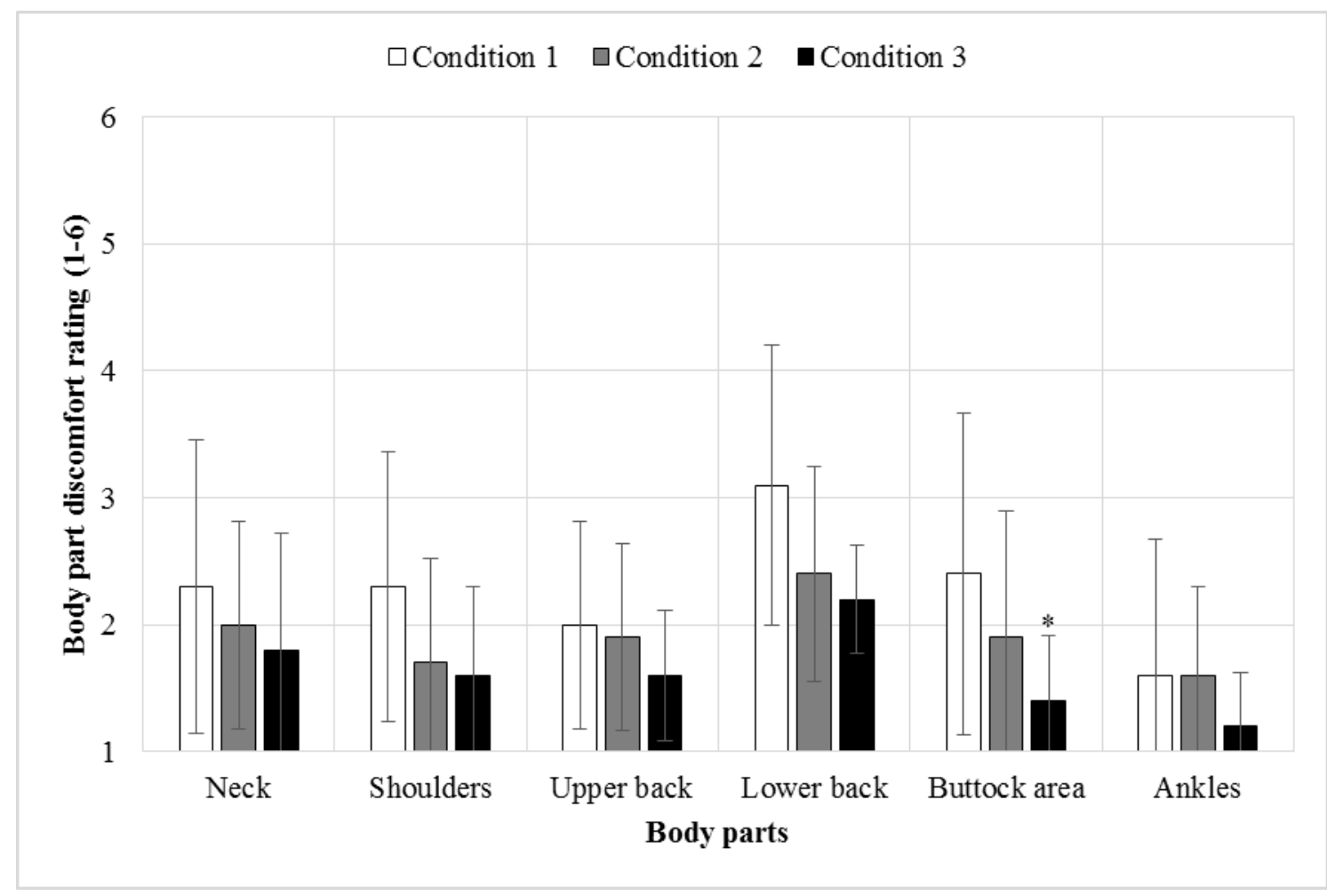

Fig. 3. Body part discomfort ratings for Condition 1 (no movement), 2 (fore-aft) and 3 (cushion and backrest angle) after 60 minutes of driving $(* \mathrm{p}<0.05)$.

A Wilcoxon signed-rank test also showed that there were statistically significant differences between the start ( 0 minutes) and end of the trial (60 minutes) for the three conditions for body part and overall discomfort with better ratings at the end of the trial. Wellbeing ratings were also better at the end of the trial.

Regarding the wellbeing ratings at 60 minutes (Fig. 4), there was again a trend (not statistically significant) for the two movement conditions (Condition 2 and 3) to have more positive ratings than Condition 1 (no movement) for the descriptors 'I feel relaxed', 'I do not feel physically fatigued', 'I do not have heavy legs'. Condition 3 had higher ratings than Condition 1 (no movement) for all the descriptors. van Veen et al.'s (2015) study also found more positive ratings of experiential feelings such as feeling more active, energetic, stimulated, accepting and calm. 


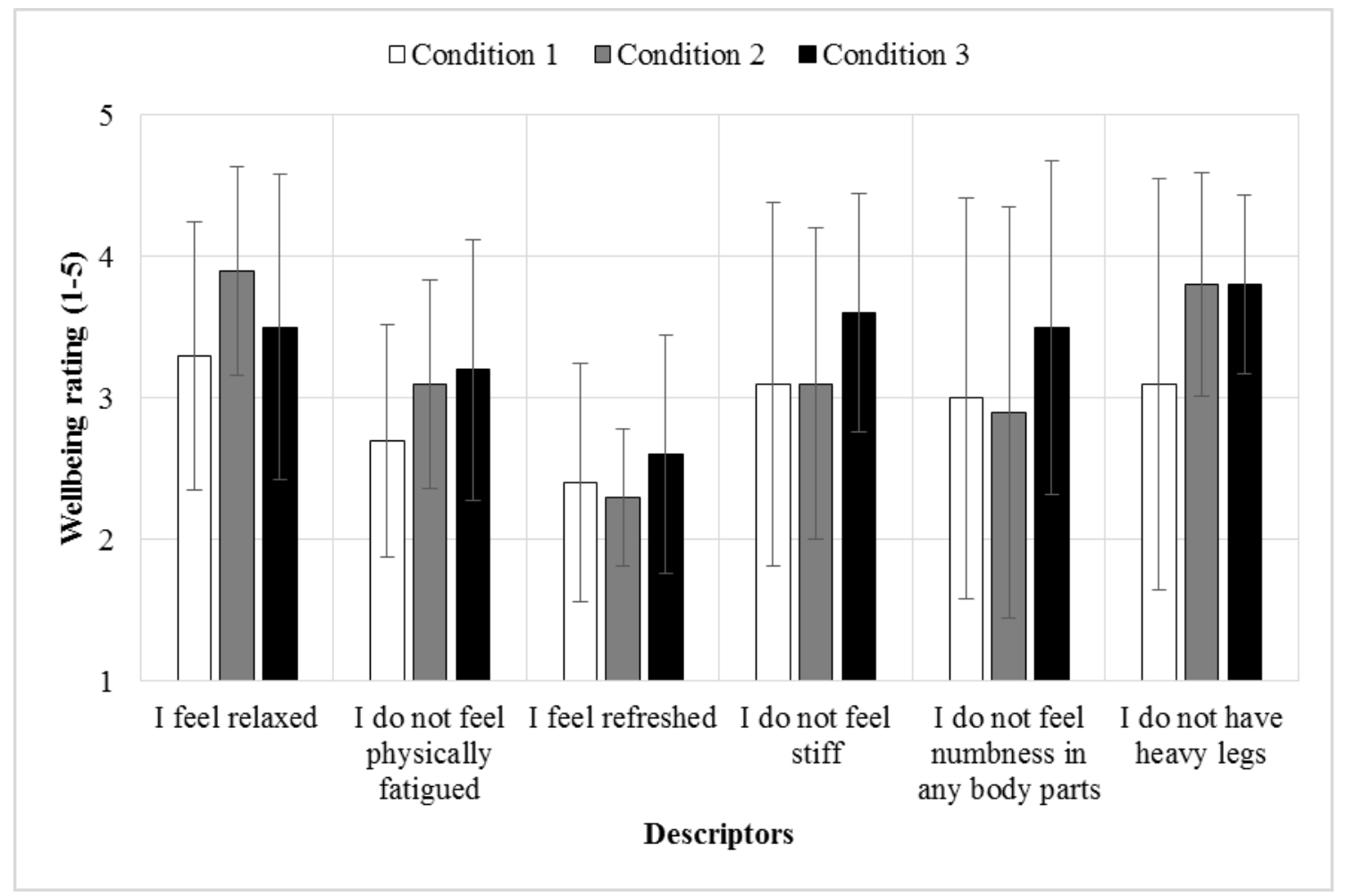

Fig. 4. Wellbeing ratings for Condition 1 (no movement), 2 (fore-aft) and 3 (cushion and backrest angle) after 60 minutes of driving.

Posture scores verified that as expected driver posture was fairly static during the 60 minute simulated drive. Similar postures were adopted (within individuals) for all three conditions. Moreover, total posture scores were low indicating no 'at risk' postures with this highly adjustable seat.

The SFMs analysis showed that, as with other studies (e.g., Sammonds et al., 2017a), SFMs frequency generally increased over time during driving (Fig. 5). There was a trend for a higher SFMs frequency in the final 15 minute period (i.e., 45-60 minutes) with the two movement conditions, but this was not significant. Sammonds et al. (2015) observed a relationship between overall discomfort and SFMs frequency over a 130 minute simulated drive, however this was not statistically evidenced. A similar trend was also observed with our data for overall discomfort for all seat conditions, comparing SFMs frequency at the start of the trial ( 0 -15 minutes) with the end of the trial (45-60 minutes), Condition $1, \mathrm{p}=0.01$; Condition $2, \mathrm{p}=0.089$; Condition $3, \mathrm{p}=0.056$. It should also be noted that there was a lot of variation in the number of SFMs between individuals throughout all trials.

It is interesting that the frequency of SFMs was higher for the two movement conditions than the control: it may be that seat movement encourages a small shift in posture which is beneficial to the body. However, other authors for example, Maradei et al. (2017) who measured repositioning movements and van Veen (2015) who measured body movements found more 'driver movement' with their static seat condition. The discrepancy could be due to differences in experimental design, seat movement type, and different criteria used to monitor the frequency of driver movements. It was also observed that the mean SFMs for the whole 
60 minute drive was higher and showed more variation in females than in males for all conditions (Condition 1 - females 11.20 (SD 10.99), males 6.8 (SD 4.87); Condition 2 - females 14.80 (SD 6.87), males 7.80 (SD 5.36); and Condition 3 - females 15.2 (SD 11.05), males 8.20 (SD 2.28). A gender difference was not reported by other researchers.

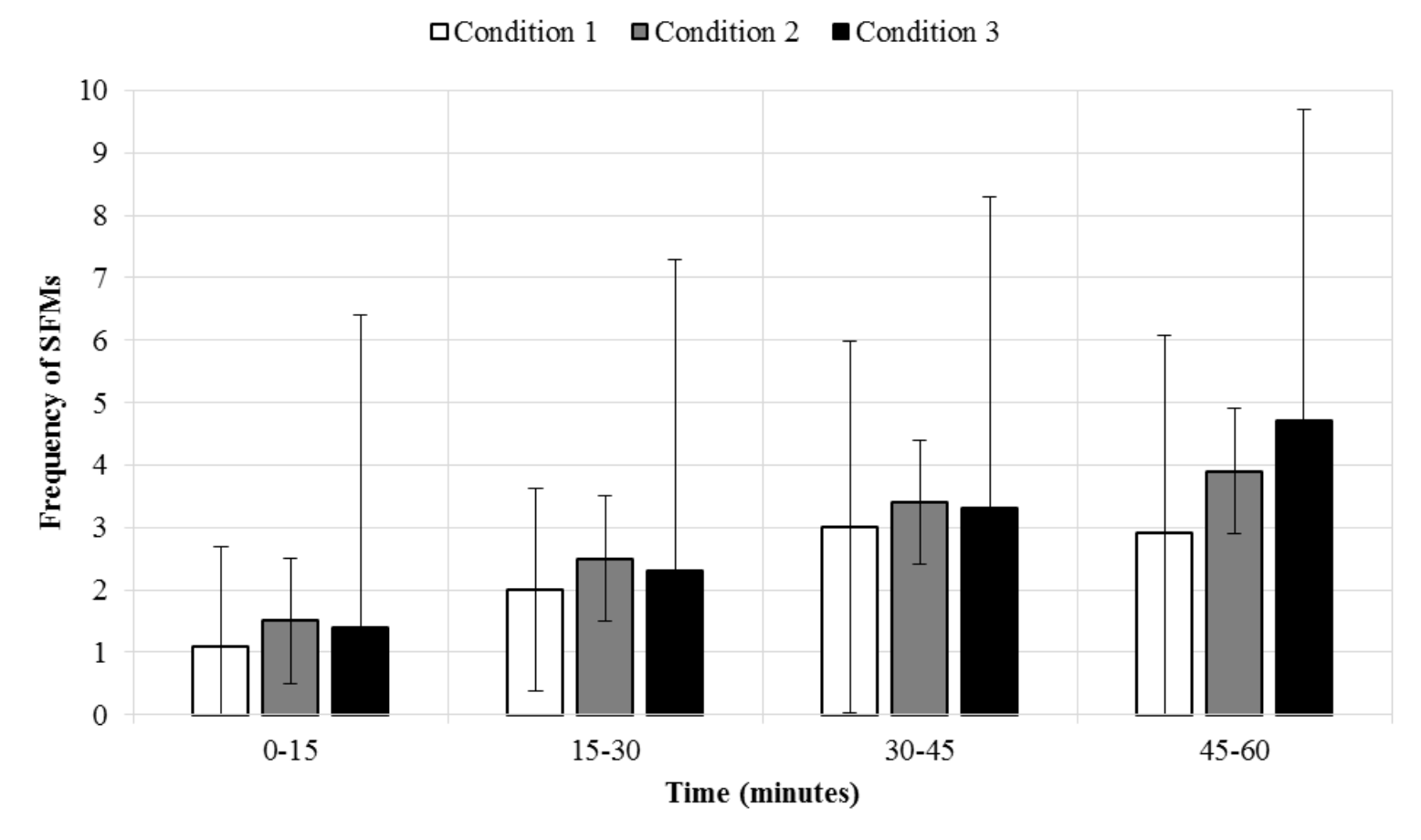

Fig. 5. Mean frequency of SFMs with time spent driving.

Concerning comments from the de-brief questionnaire conducted at the end of the final session, it can be inferred that the concept of seat movement was well received by the majority of participants. They realized that they were more uncomfortable with 'no seat movement' than the two 'seat movement' conditions. Although the majority of participants were well aware of the actual seat movement itself they were not able to identify which movement was produced in each session. Feedback was given regarding positive effects of the resultant repositioning and small body movements, as well as feelings of awakening, alertness, and improved concentration. Additionally, all participants felt that the seat movement did not disturb their driving. Finally, none of the participants noticed the sound produced by the seat movement itself. Typical comments are reproduced below but they will require exploration in future studies.

"I kind of adjusted to the movement. I felt re-energized in my position, it awakened me."

"The movement felt refreshing, it helps."

"The seat movement felt about right, otherwise I felt that discomfort would increase."

Although the ranges of seat movement tested were relatively small, there was a beneficial effect on drivers. It is interesting that the movement introduced was still greater than previous studies, for example Van Veen et al, 2015, used $+1^{\circ}$ to -1 seat cushion tilt and Maradei et al, 2017 , used $+5^{\circ}$ to -5 seat tilt. It is difficult to speculate why this might be, but it is likely to be 
due to differences in experimental design, for example seat type (e.g. high-end leather seat), type of seat movement, and the way the movement was introduced (i.e., very slow, fixed speed, smooth, and in increments). Also as movement was very slow, it was barely perceptible: this may have allowed participants time to adjust to the movement between incremental movements. Vehicle seat comfort is multidimensional (Kolich, 2008), therefore the range and exact nature of movement introduced is clearly is dependent on the driver cabin set-up (and driver anthropometry) and needs more exploration in future studies.

The main limitation of this study is that it was conducted in the laboratory environment with simulated driving. However, due to cost and safety constraints it would be difficult to explore these seat movement concepts in the field with a production car and prototype seats. Simulated driving also affects the driving itself, for example, driver posture, concentration required, driver motivation. Moreover, real driving conditions, such as traffic conditions, road conditions, environment sounds, may influence awareness of the seat movements. It should also be noted that music can positively influence the comfort experience (Kruithof et al. 2014), such that ratings of discomfort may have been higher for all three conditions. However, as this was standardized across the trials it should not affect the findings. The repetitive nature of these laboratory sessions could promote monotonous driving and a decrease in expectations throughout the sessions, but the balanced order of the sessions helped to reduce this risk and no order effect was found. Although Van Veen et al (2015) mentioned that some participants expressed disappointment when they realized the seat would not execute movements during the subsequent session, this was not found in our study.

The current study also involved 60 minutes of simulated driving with vibration; the results may have been more statistically sound if the trials were of longer duration. However, as the study involved three sessions on different days, there was a concern about participant dropout with longer sessions. Also, the 60 minute trial duration was selected to explore early signs of discomfort. Moreover, there may have been more statistically significant differences between the seat conditions if we had used a standard/lower end production seat. However, we needed to select a high-end production seat because of the range of electronic adjustability it offered.

Finally, the methodology worked well at distinguishing between the seat conditions although a larger number of participants would increase validity. SFMs is a relatively new technique to capture driver behavior, but more research is needed to standardize the criteria used to define driver movements. Although the SFMs technique was modified (and added to) it is also important to note that a significant input of time was needed by the researchers to increase the reliability of judgements for quantification.

\section{Conclusions}

Seat movement (i.e., fixed speed, slow, smooth, relatively small range, slightly perceptible) appears to have a beneficial effect on drivers (in simulated driving) in terms of lower ratings of discomfort over time, particularly in the buttock area. Wellbeing ratings were also better for the seat movement conditions. 
SFMs were higher for the seat movement conditions; it may be that seat movement encourages a small shift in posture which is beneficial to the body. However, this needs more exploration by researchers.

Seat movement was well received by participants and did not disturb the driver experience. Positive effects were reported with regard to the resultant repositioning and small body movements, feelings of awakening, alertness, and improved concentration. Again, these require further exploration.

It is recommended that any seat movement introduced to the driving seat is slow, smooth, and small to minimize the effect on the driving task. However, the exact nature of this movement is likely to be dependent on individual factors (e.g. anthropometry), seat design (e.g. shaping) and the driver cabin space (e.g. steering wheel/pedal position).

Further research is being conducted by the team to explore in more detail the seat movement itself, when it is perceived, driver views on the concept and acceptability while driving.

\section{Acknowledgments}

We would like to acknowledge the EPSRC Industrial CASE award and Nissan Motor Company Ltd. for funding this research (ID: GR-0417).

\section{References}

Ahmadpour, N., Robert, J.-M. and Lindgaard, G., 2015. Aircraft passenger comfort experience: underlying factors and differentiation from discomfort. Applied Ergonomics, 52, pp.301-8.

Borg, E. and Borg, G., 2002. A comparison of AME and CR100 for scaling perceived exertion. Acta Psychologica, 109 (2), pp.157-75.

Franz, M., Zenk, R., Vink, P., Hallbeck, S., 2011. The effect of a light weight massage system in a car seat on comfort and electromyogram. J Manipulative and Physiological Therapeutics 34(2), 107-113.13.

Grieco, A., 1986. Sitting posture: An old problem and a new one. Ergonomics, 29(3), 345-62.

Groenesteijn, L., Ellegast, R.P., Keller, K., Krause, F., Berger, H. and de Looze, M.P., 2012. Office task effects on comfort and body dynamics in five dynamic office chairs. Applied Ergonomics, 43(2), pp.320-8.

Gruevski, K.M., Holmes, M.W., Gooyers, C.E., Dickerson, C.R. and Callaghan, J.P., 2016. Lumbar postures, seat interface pressures and discomfort responses to a novel thoracic support for police officers during prolonged simulated driving exposures. Applied Ergonomics, 52, 160-168.

Gyi, D.E., 2013. Driving posture and healthy design. In: N. Gkikas, ed. Automotive ergonomics: driver-vehicle interaction. Boca Raton: CRC Press. pp.123-32.

Gyi, D.E. and Porter, J.M., 1999. Interface pressure and the prediction of car seat discomfort. Applied Ergonomics, 30, 99-107.

Helander, M.G. and Zhang, L., 1997. Field studies of comfort and discomfort in sitting. Ergonomics, 40(9), 895-915.

Hiemstra-van Mastrigt, S., Kamp, I., Van Veen, S.A.T., Vink, P. and Bosch, T., 2015. The influence of active seating on car passengers' perceived comfort and activity levels. Applied Ergonomics, 47, 211-219. 
Holmes, M.W.R., McKinnon, C.D., Dickerson, C.R. and Callaghan, J.P., 2013. The effects of police duty belt and seat design changes on lumbar spine posture, driver contact pressure and discomfort. Ergonomics, 56(1), 126-136.

International Organization for Standardization, 1997. ISO 2631-1: 1997. Mechanical vibration and shock - eva-luation of human exposure to whole-body vibration. Part 1: General requirements. Geneva: International Organisation for Standardization.

Jagannath, M. and Balasubramanian, V., 2014. Assessment of early onset of driver fatigue using multimodal fatigue measures in a static simulator. Applied Ergonomics, 45 (4), pp.1140-7.

Kolich, M., 2008. A conceptual framework proposed to formalize the scientific investigation of automobile seat comfort. Applied Ergonomics, 39, 15-27.

Kolich, M. and Taboun, S.M., 2002a. Combining psychophysical measures of discomfort and electromyography for the evaluation of a new automotive seating concept. International Journal of Occupational Safety and Ergonomics, 8(4), 483-96.

Kolich, M. and Taboun, S.M., 2002b. The effect of microadjustment on low back comfort in the context of automotive seating. International Journal of Vehicle Design, 29(4), 376-89.

Kolich, M., Taboun, S.M. and Mohamed, A.I., 2001. Electromyographic comparison of two lumbar support mechanisms intended for automotive seating applications. Proceedings of the Institution of Mechanical Engineers, Part D: Journal of Automobile Engineering, 215(7), 771-7.

Kruithof, A., Visch, V., Vink, P., Pedgley, O., 2014. Comfort Design Through Music and Emotion: Effects of Passengers' Activities on Comfort. Proceedings of the 5th International Conference on Applied Human Factors and Ergonomics AHFE 2014, Kraków, Poland 19-23 July 2014. Edited by T. Ahram, W. Karwowski and T. Marek.

Malik, L. Jurgens, H. and Helbig, K., 1991. Quantitative Analysis of Involuntary Movements as a Test of Comfort of a Car Seat: A Study of Man-Machine Interface, 1, 53-61.

Mansfield, N., Sammonds, G. and Nguyen, L., 2015. Driver discomfort in vehicle seats - effect of changing road conditions and seat foam composition. Applied Ergonomics, 50, pp.153-9.

Mansfield, N.J. and Griffin, M.J., 2000. Difference thresholds for automobile seat vibration. Applied Ergonomics, 31(3), 255-261.

Maradei, F., Quintana, L. and Castellanos, J., 2017. Influence of seat tilt motion on discomfort perception during a simulated driving activity. Work, 56(1), 99-110.

McAtamney, L. and Corlett, E.N., 1993. RULA: a survey method for the investigation of work-related upper limb disorders. Applied Ergonomics, 24(2), pp.91-9.

Parakkat, J., Pellettiere, J., Reynolds, D., Sasidharan, M. and El-Zoghbi, M., 2006. Quantitative methods for determining U.S. air force crew cushion comfort. SAE Technical Paper Series, (2006-01-2339), 1-12.

Porter, J.M. and Gyi, D.E. 2002. The prevalence of musculoskeletal troubles among car drivers. Occupational Medicine, 52(1), 4-12.

Porter, J.M. and Gyi, D.E., 1998. Exploring the optimum posture for driver comfort. International Journal of Vehicle Design, 19(3), pp.255-66.

Sammonds, G.M., Fray, M. and Mansfield, N.J., 2017a. Effect of long term driving on driver discomfort and its relationship with seat fidgets and movements (SFMs). Applied Ergonomics, 58, pp.119-27.

Sammonds, G.M., Mansfield, N.J. and Fray, M., 2017b. Improving long term driving comfort by taking breaks - How break activity affects effectiveness. Applied Ergonomics, 65, 8189. 
Sheridan, T.B., Meyer, J.E., Roy, S.H., Decker, K.S., Yanagishima, T. and Kishi, Y., 1991. Physiological and psychological evaluations of driver fatigue during long term driving. SAE Technical Paper Series, (910116), 1-10.

Smith, J., Mansfield, N. and Gyi, D., 2015. Long-term discomfort evaluation: comparison of reported discomfort between a concept elevated driving posture and a conventional driving posture. Procedia Manufacturing, 3, pp.2387-94.

van Veen, S.A.T., Orlinskiy, V., Franz, M. and Vink, P., 2015. Investigating car passenger well-being related to a seat imposing continuous posture variation. Journal of Ergonomics 5 (3) doi: 10.4172/2165-7556.1000140.

Vergara, M. and Page, A., 2002. Relationship between comfort and mobility in sitting posture. Applied Ergonomics, 33, 1-8.

Zhang, L., 1996. Identifying factors of comfort and discomfort in sitting. Human Factor, $38(3), 377-389$. 